\title{
Nickel-Catalyzed Decarboxylative Coupling of Redox-Active Esters with Aliphatic Aldehydes
}

\author{
Jichao Xiao, Zhenning Li, and John Montgomery*
}

Department of Chemistry, University of Michigan, 930 N. University Ave. Ann Arbor, MI 48109-1055,

Email: jmontg@umich.edu

\begin{abstract}
The addition of alkyl fragments to aliphatic aldehydes is a highly desirable transformation for fragment couplings, yet existing methods come with operational challenges related to the basicity and instability of the nucleophilic reagents commonly employed. We report herein that nickel catalysis using a readily available bioxazoline $(\mathrm{BiOx})$ ligand can catalyze the reductive coupling of redox-active esters with aliphatic aldehydes using zinc metal as the reducing agent to deliver silyl-protected secondary alcohols. This protocol is operationally simple, proceeds under mild conditions, and tolerates a variety of functional groups. Initial mechanistic studies suggest a radical chain pathway. Additionally, alkyl tosylates and epoxides are suitable alkyl precursors to this transformation providing a versatile suite of catalytic reactions for the functionalization of aliphatic aldehydes.
\end{abstract}

Cross-coupling reactions have revolutionized the landscape of carbon-carbon bond construction, with extensive application in the synthesis of natural products, pharmaceuticals, agrochemicals, and functionalized polymers. ${ }^{1}$ Coupling of Grignard or organolithium reagents with carbonyl compounds remains among the most frequently used synthetic reactions (Figure 1A), ${ }^{2}$ although limitations exist due to the instability, basicity, and lack of functional group compatibility of the requisite highly nucleophilic reagents. Barbier-type reactions ${ }^{3}$ and Nozaki-Hiyama-Kishi $(\mathrm{NHK})^{4}$ couplings are attractive as they avoid the handling of air- and moisture-sensitive organometallic reagents, and have been employed in many complex settings, ${ }^{5}$ although the reaction scope is often limited in cases where $\mathrm{sp}^{3}$ alkyl fragments are added to aliphatic enolizable aldehydes.

An attractive approach to deliver organohalide feedstocks to carbonyl compounds that obviates the need for preformed organometallic reagents are transition-metal-catalyzed reductive coupling reactions. ${ }^{6}$ To date, the coupling of aldehydes with organohalides using a stoichiometric reducing agent can be catalyzed by $\mathrm{Cr},{ }^{7} \mathrm{Rh},{ }^{8} \mathrm{Co},{ }^{9}$ and $\mathrm{Ni},{ }^{10}$ but current systems are often restricted to aryl, allylic or propargylic halides and aromatic aldehydes. The catalytic transformation of aliphatic aldehydes with less-activated $\mathrm{sp}^{3}$ counterparts remains a synthetic challenge. ${ }^{7 c-e, 11}$ Aliphatic aldehydes often exhibit attenuated reactivity, and competing enolization reactions lead to side product formation. ${ }^{10 \mathrm{~d}}$ Additionally, compared with $\mathrm{sp}^{2}$-hybridized halides, unactivated alkyl halides are less suitable coupling partners due to lower reactivity and undesirable side pathways such as homocoupling or competing $\beta-\mathrm{H}$ eliminations of reactive intermediates. ${ }^{12}$

The wide availability of alkyl carboxylic acids makes this substrate class an attractive coupling partner for processes of this type. ${ }^{13}$ In recent studies, Baran, Weix, and others have extensively explored the utility of redox-active esters (RAEs), as a carboxylic acid-derived radical precursors in a variety of carbon-carbon and carbon-heteroatom bond forming reactions. ${ }^{14}$ While the specific combination of aliphatic, enolizable aldehydes with $\mathrm{sp}^{3}$ alkyl fragments are largely excluded from 
past work, Reisman, Blackmond, and Baran recently reported an attractive electrochemical $\mathrm{Cr}$ catalyzed cross-coupling of aldehydes with redox-active esters including two examples of this combination with primary RAEs (Figure 1B), ${ }^{11 \mathrm{~b}}$ but no general approach to the catalytic union of aliphatic aldehydes with simple $\mathrm{sp}^{3}$ alkyl fragments has been described.

In order to address this gap in the field, our lab recently described a catalytic process involving the reductive coupling of aliphatic aldehydes with alkyl bromides in a pathway proposed to proceed through the intermediacy of $\alpha$-silyloxyalkylnickel intermediates derived from aldehydes, silyl chlorides, and low-valent nickel (Figure 1B). ${ }^{15}$ In order to address limitations of that protocol, including substrate access, scope, and yield, we have now explored the utility of more broadly available substrate classes in catalytic couplings with aliphatic aldehydes (Figure 1C). The main focus of this study is the coupling of aliphatic aldehydes with redox-active esters, providing access to numerous product types derived from simple carboxylic acid precursors. Additionally, preliminary examples of reductive couplings between aldehydes and alkyl tosylates or epoxides ${ }^{14 w, 16}$ are described. This combination of procedures provides strategies where alkyl fragments are derived from carboxylic acids, alcohols, or alkenes, thus greatly expanding the range of precursors available for aldehyde functionalization processes.

Figure 1. Background and focus of this work.
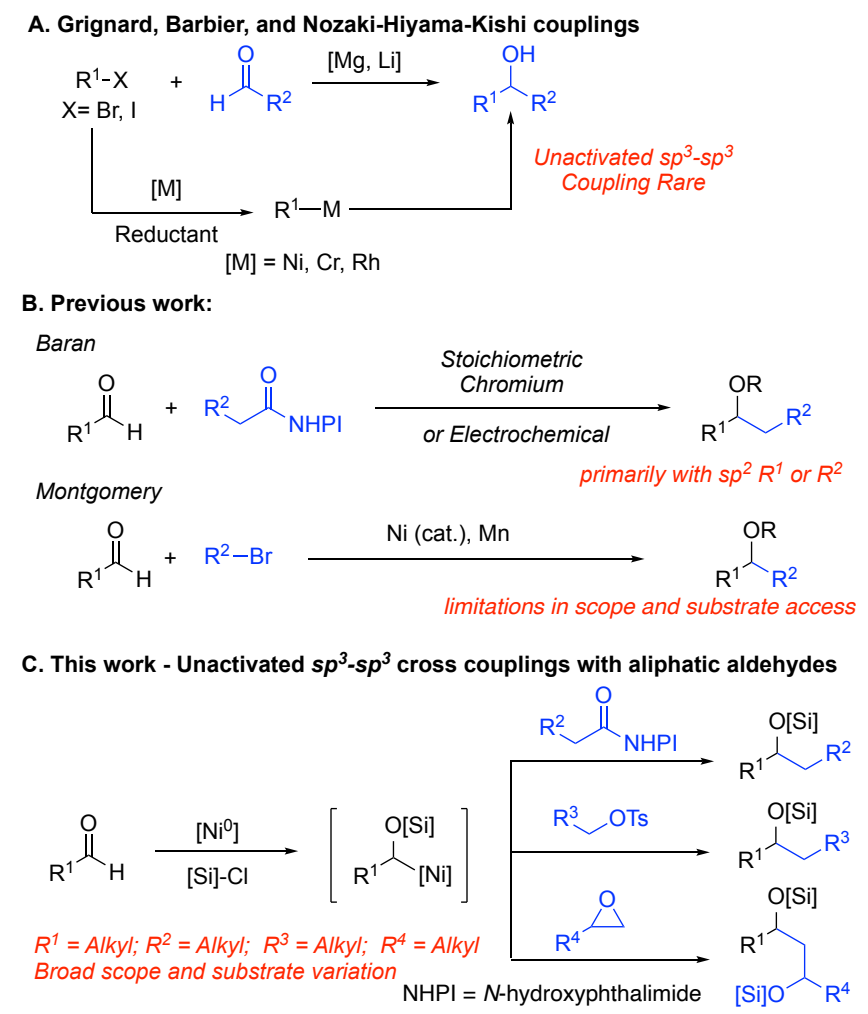

Our initial investigation geared towards developing the catalytic reductive coupling of aldehydes 1a with the $\mathrm{N}$-hydroxyphthalimide (NHPI) ester $\mathbf{2 a}$ (Table 1). Systematic investigation of the reaction parameters showed that the desired product 3a was isolated in good yield (91\%) with a combination of $\mathrm{Ni}(\mathrm{cod})_{2}$ and bioxazoline ( $\mathrm{BiOx}$ ). Control experiments indicated that a nickel catalyst was necessary for the reaction to proceed, and other nickel sources only led to moderate yield (entries 2, 11 and 12). The ligand (BiOx), reductant (nanopower $\mathrm{Zn}$ ), 1,5-hexadiene and $\mathrm{LiCl}$ also 
played a crucial role in successful transformation (entries 3-6). A ligand screen revealed that $\mathrm{BiOx}$ is uniquely effective when compared with other common ligands (entries 13-15). Of note, olefin additives can dramatically improve the efficiency, with 1,5-hexadiene proving the most effective (entries 5, 8-10). Furthermore, the particle size of $\mathrm{Zn}$ is critical, with the use of nanopowder $\mathrm{Zn}$ (40$60 \mathrm{~nm}$ ) enhancing the yield (entry 7 ).

Table 1. Optimization of Reaction Conditions

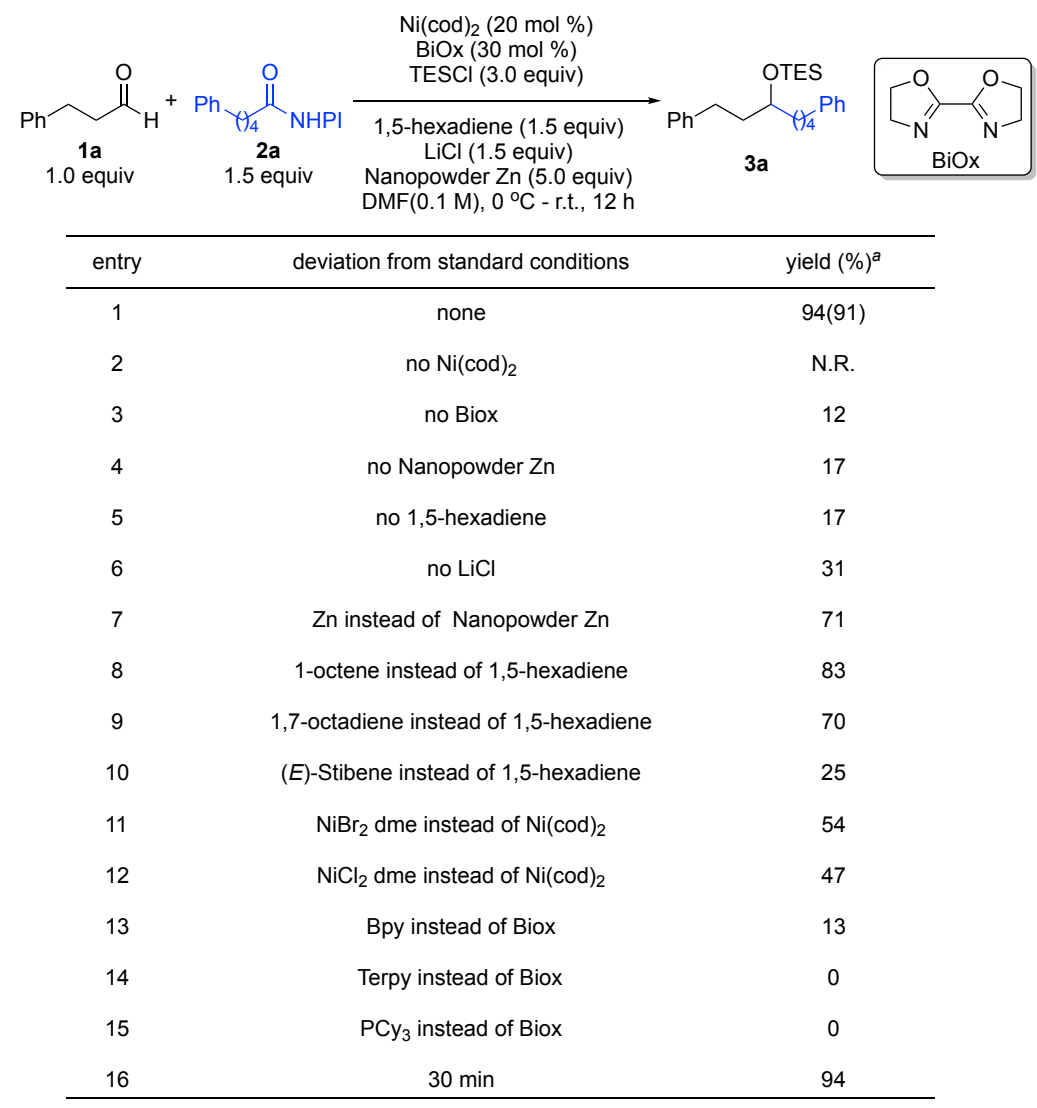

aYields were determined by GC with $n$-tridecane as the internal standard. Isolated yield is given in parentheses $\left(0.2 \mathrm{mmol}\right.$ scale). Diastereomeric ratios were determined by ${ }^{1} \mathrm{H}$ NMR analysis. TES $=$ triethylsilyl.

With optimal conditions in hand, we sought to define the reaction scope (Table 2A). Various $1^{\circ}$ and $2^{\circ}$ carboxylic acids were converted to the corresponding NHPI-esters and coupled efficiently with aldehyde $1 \mathbf{a}$. A range of functional groups were well tolerated including ketones $(\mathbf{3 h}, \mathbf{3 i}, \mathbf{3} \mathbf{a b})$, esters (3j, 3x), N-Boc (3y), N-tosyl (3z), and alkenes (3g, 3v, 3ac, 3ad). A simple methyl group can also be added effectively using the RAE $3 c$ derived from acetic acid. Notably, some potentially reactive functional groups, including alkyl chloride $\mathbf{3} \mathbf{k}$ and aryl bromide $\mathbf{3} \mathbf{l}$ were left intact under current conditions, offering opportunities for subsequent cross-coupling. Protected alcohols (3f, 3ac) and ethers (3m, 3t, 3u) were also competent coupling partners, allowing for the construction of polyol motifs. Moreover, heterocycles including pyridine (3o), and indole (3p) were also readily accommodated as were a series of secondary redox-active esters (3q-3z). The protocol was scalable to $5 \mathrm{mmol}$, obtaining the desired product $3 \mathrm{a}$ in $81 \%$ isolated yield.

After defining the scope of RAEs, attention then turned to the scope of the aliphatic aldehyde 
component (Table 2B). Sterically encumbered aldehydes with $\beta$-branching, such as isovaleraldehyde (3af) and citronellal (3ag) were competent coupling partners. $\alpha$-Branched aldehydes (3as-3au) also delivered the desired products without diminished efficiency. Benzyl ethers (3ah), silyl ethers (3ai), acetals (3aj), alkynes (3ak), and phthalimide groups (3ar) were also tolerated. Substrates with functional groups known to engage in transition-metal-catalyzed transformations such as aryl chlorides (3al), aryl bromides (3am) and aryl boronate esters (3an), delivered the desired product smoothly without competing reactivity. Notably, heterocycle substrates, such as indole (3aq), was likewise suitable for this chemistry. The scope and chemoselectivity of this method in activating aldehydes in the presence of a wide array of reactive functional groups including ketones is thus quite broad, addressing an important limitation of classical methods for carbonyl additions.

Table 2. Scope of Catalytic Couplings of Aldehydes and Redox-active Esters. ${ }^{a}$

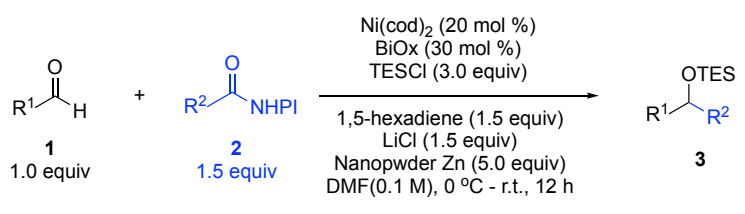

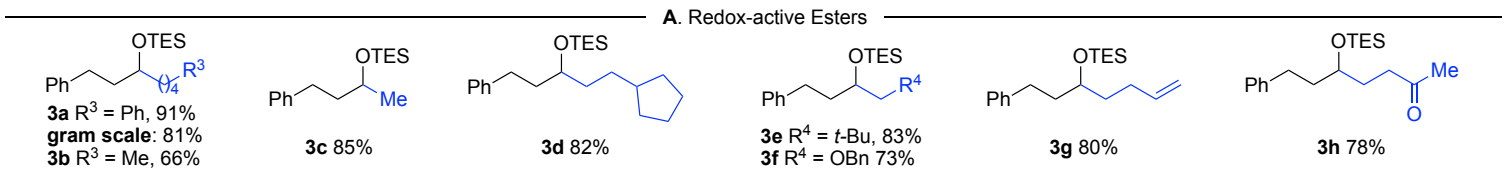
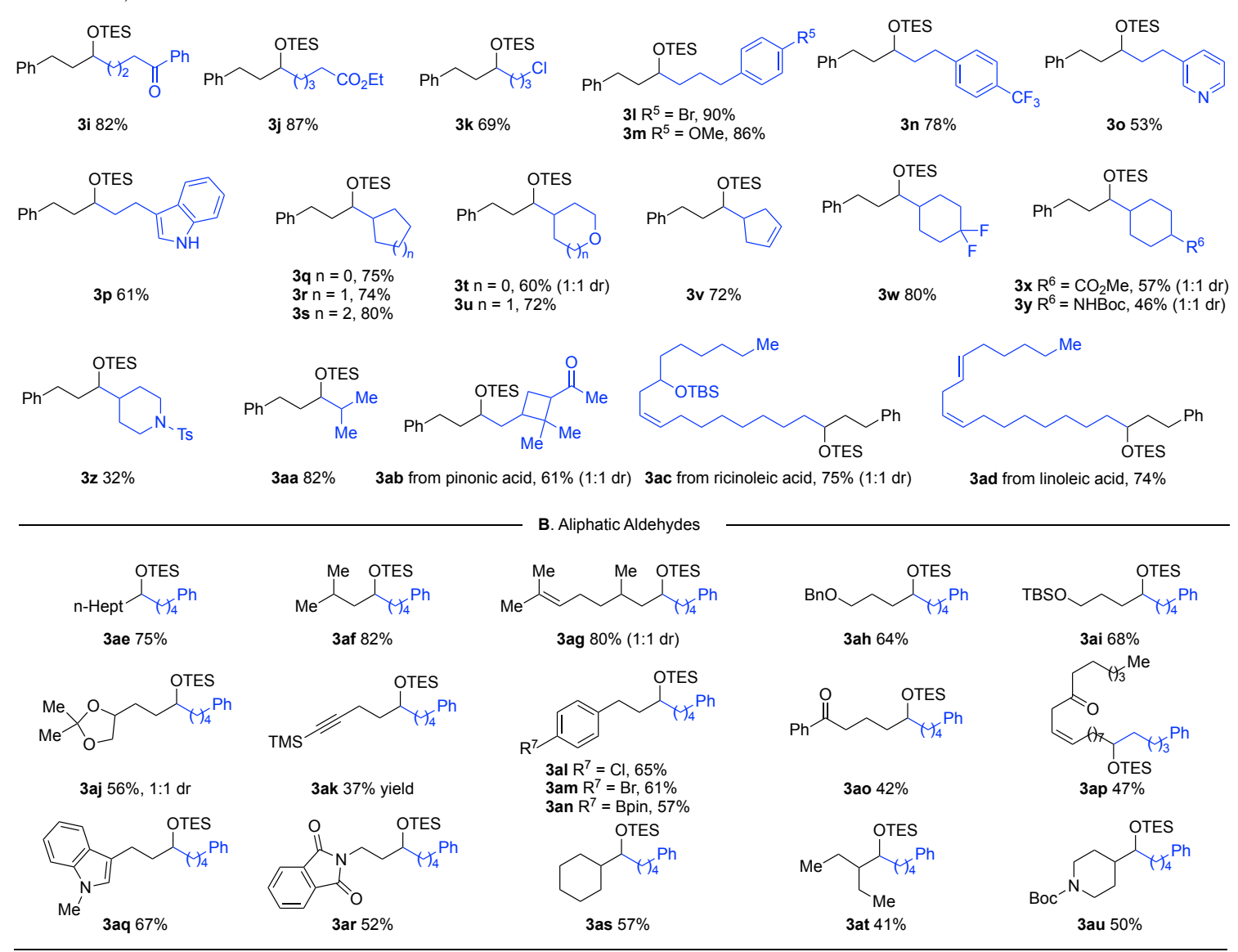

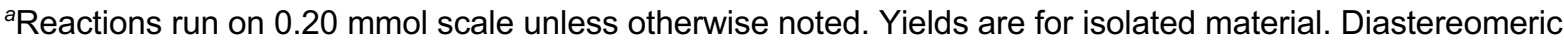
ratios were determined by ${ }^{1} \mathrm{H}$ NMR analysis. TES $=$ triethylsilyl. Ts $=p$-toluenesulfonyl. 
While this method demonstrates considerable scope with carboxylic acid-derived RAEs, we considered that utilizing alkyl precursors derived from simple alcohols and alkenes would further extend the utility and scope of the strategy (Table 3). To enable the use of alcohol precursors, we explored the use of alkyl tosylates as the coupling partner. ${ }^{17}$ With simple modification of the reaction conditions (see $\mathrm{SI}$ ), our catalytic system can activate the $\mathrm{C}-\mathrm{O}$ bond of tosylates, delivering the desired product in good yield (Table 3 ) with attractive functional group compatibility including esters (5b), ethers (5c), and furans (5d).

With an eye towards utilizing alkene feedstocks, we then considered the use of epoxides as the alkyl precursor (Table 3). ${ }^{18}$ After extensive investigation of reaction parameters (see SI), an effective method was realized, obtaining the desired silyl-protected 1,3-diols in good yield, tolerating a range of functional groups, such as furans (7c), ethers (7d), aryl bromides (7e), and alkynes (7f). This approach further diversifies the range of product types accessible by this method, with 1,3-diols being obtained in the epoxide-based procedure. ${ }^{19}$

Table 3. Catalytic Couplings of Aldehydes with Alkyl Tosylates or Epoxides. ${ }^{a}$

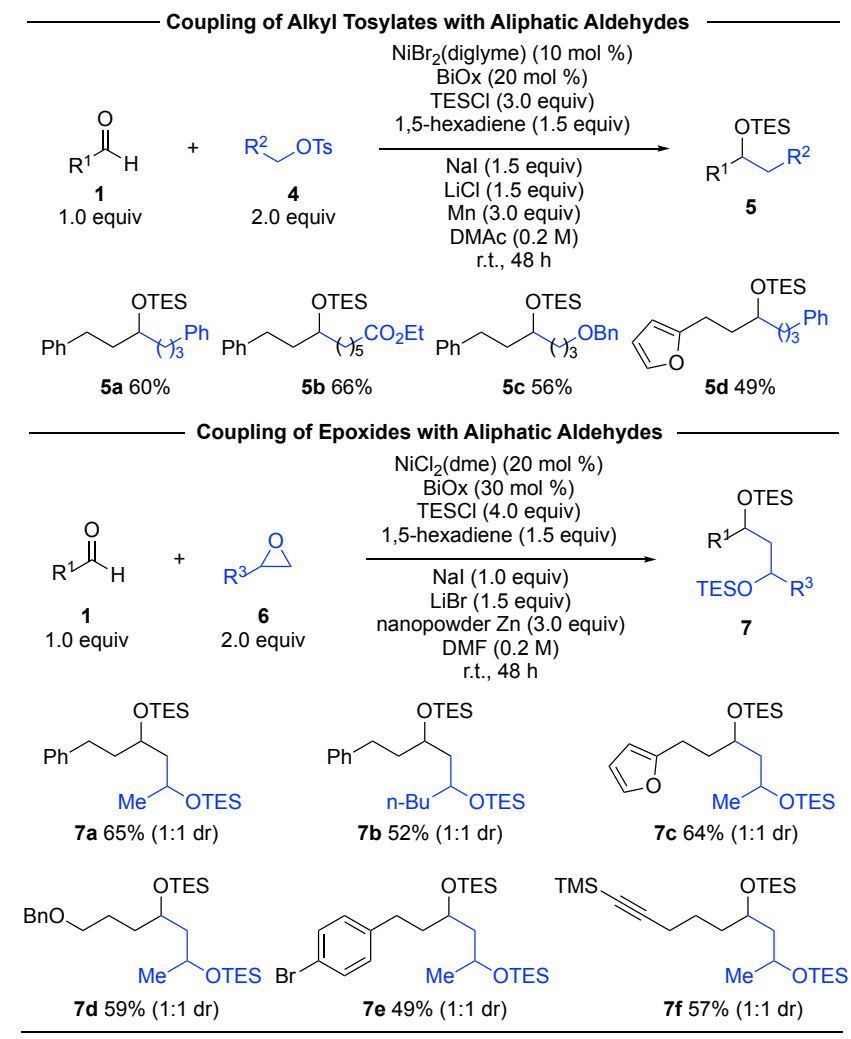

${ }^{a}$ Reactions run on $0.20 \mathrm{mmol}$ scale unless otherwise noted. Yields are for isolated material.

Diastereomeric ratios were determined by ${ }^{1} \mathrm{H}$ NMR analysis. TES $=$ triethylsilyl.

A cyclopropane-containing RAE $\mathbf{8}$ afforded a $92: 8$ ratio of ring-opened product $\mathbf{3 g}$ and compound 9 with the cyclopropane ring intact (Figure 2A). Additionally, in an experiment involving hexenyl transfer, a direct linear dependence of the ratio of 11/12 on the catalyst loading was observed (Figure 2B). These experiments are consistent with a mechanism involving free-radical intermediates, in analogy to prior studies on nickel-catalyzed processes with both alkyl halides or 
redox-active esters. ${ }^{14 v, 20}$ Similarly, ring opening was observed in couplings of cyclopropanecarboxaldehyde (13) leading to product 14 exclusively as the Z-isomer (Figure 2C). In this case, we attribute ring-opening of the cyclopropane unit to a nickel-catalyzed process involving the intermediacy of 15, potentially involving the initial oxidative addition of a low-valent nickel species to the aldehyde, promoted by $\mathrm{Et}_{3} \mathrm{SiCl}^{15,21}$ An experiment employing stoichiometric $\mathrm{Ni}(\operatorname{cod})_{2}$ but lacking the zinc reductant resulted in the formation of product $3 \mathbf{a}$ in high yield, suggesting that key organonickel intermediates involved in product formation do not require reduction at the nickel center, but rather that the zinc reductant is involved in catalyst regeneration (Figure 2D).

Figure 2. Mechanistic Experiments

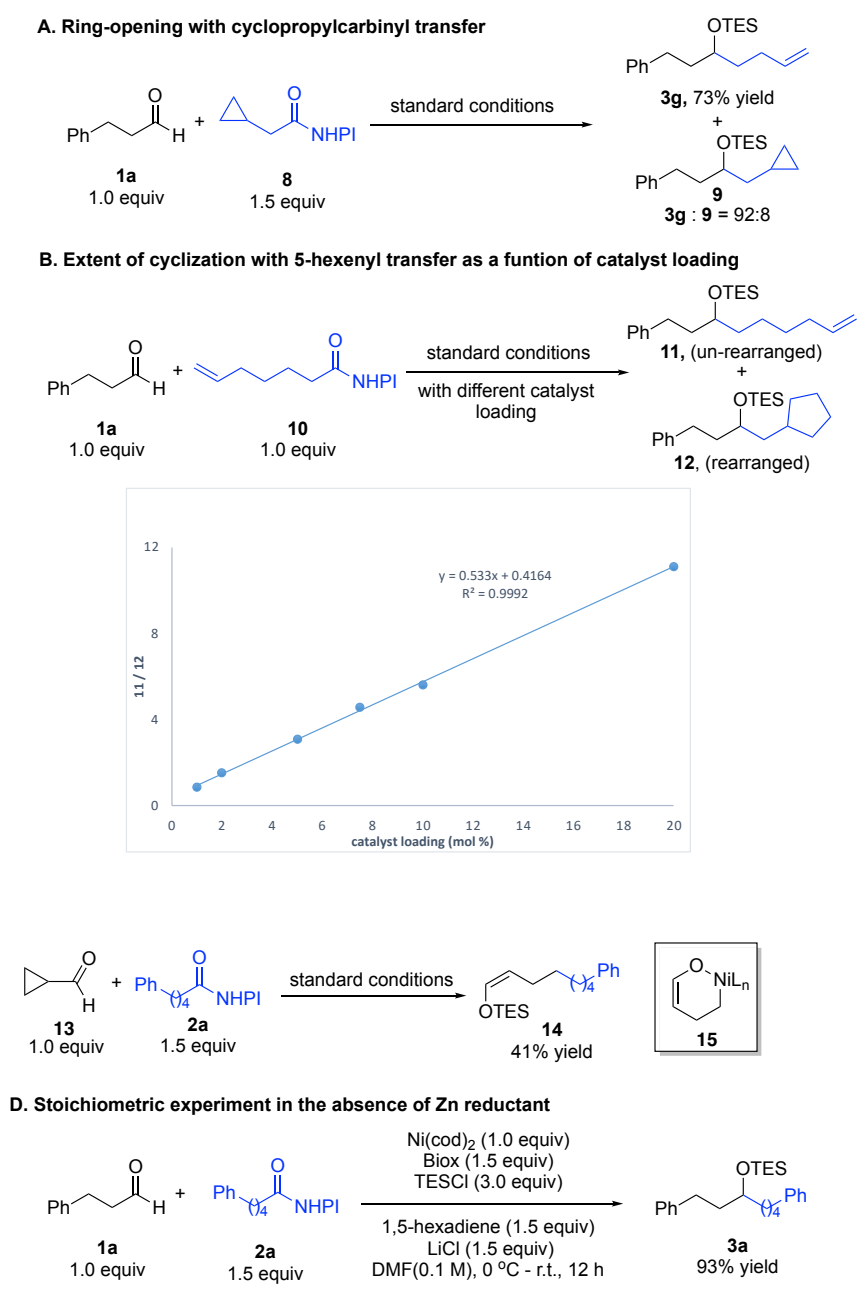

Based on these experiments and insights from prior studies, we propose a mechanistic picture consistent with the above findings (Figure 3). Oxidative addition of aldehyde 1 and silyl chloride to $\mathrm{Ni}(0)$ generates $\mathrm{Ni}(\mathrm{II})$ silyloxyalkyl complex II. Species related to II have been previously described, ${ }^{22}$ and our prior studies of aldehyde - alkyl halide couplings illustrated characteristic byproducts that are best explained by the involvement of II. Addition of free radical VI to II affords $\mathrm{Ni}(\mathrm{III})$ species III, which undergoes rapid reductive elimination to form product $\mathbf{3}$ and $\mathrm{Ni}(\mathrm{I})$ species IV. Combination of IV with the RAE $\mathbf{2}$ results in $\mathbf{V}$ and the free radical $\mathbf{V I}$ that recombines with species II. The above steps are consistent with the observation that $\mathrm{Ni}(0)$ undergoes product 
formation in the absence of zinc, illustrating that reduction of intermediate II to the corresponding $\mathrm{Ni}(\mathrm{I})$ complex is not strictly required for turnover. Additionally, the above evidence (Figure $2 \mathrm{~A}-\mathrm{B}$ ) for free radical intermediates derived from the RAE 2 are consistent with this proposed mechanistic pathway.

The conversion of $\mathrm{Ni}(\mathrm{II})$ complex $\mathbf{V}$ to the $\mathrm{Ni}$ (II) silyloxyalkyl nickel intermediate II requires a net two-electron reduction by zinc and oxidative addition of the aldehyde and silyl chloride. The commonly invoked reduction of nickel complex $\mathbf{V}$ to $\mathrm{Ni}(0)$ complex I completes the catalytic cycle, although this possibility must be viewed within the context of recent work from Diao that illustrates that $\mathrm{Ni}(\mathrm{II}) \mathrm{BiOx}$ complexes are more resistant to reduction compared with the corresponding $\mathrm{Ni}(\mathrm{II})$ complexes of other commonly employed pyridyl-based ligands. ${ }^{23}$ The presence of the phthalimido substituent in $\mathbf{V}$ and the interaction of $\mathbf{V}$ with the aldehyde and silyl chloride may affect the facility of this reduction by nanopowder zinc. Given these complexities, the precise nature of the conversion of $\mathbf{V}$ to II will require further investigation.

The generation of free radical VI from RAE 2 is depicted (Figure 3) as involving $\mathrm{Ni}(\mathrm{I})$ species IV in analogy to studies from Baran in the coupling of anhydrides with redox-active esters. ${ }^{11 a}$ The efficiency of product formation in the absence of zinc (Table 2D) illustrates that the nickel catalyst is competent in mediating the decomposition of redox-active esters. We observed that zinc and $\mathrm{Et}_{3} \mathrm{SiCl}$ rapidly promotes the decomposition of RAE 2, however, the presence of the nickel catalyst has a protective effect as previously described by Baran, slowing the rate of consumption of 2 compared to control experiments where the nickel catalyst is omitted (see SI). Recent studies from Rousseaux have provided evidence in reductive arylation reactions that $\mathrm{TMSCl}$ and $\mathrm{Zn}$ promote the formation of free radicals. ${ }^{24}$ Our studies, which potentially involve effects of the silyl chloride in several steps including aldehyde activation and/or redox-active ester decomposition, have not clearly elucidated the active agent in mediating radical formation from the redox-active ester. Finally, the role of 1,5-hexadiene is not illustrated in the mechanistic scheme since the 4- and 5coordinate complexes II and III cannot accommodate the bidentate coordination of this additive. Coordination of this additive likely prevents catalyst decomposition and/or inhibits competing side reactions that lie off the productive catalytic pathway.

Figure 3. Proposed Mechanism

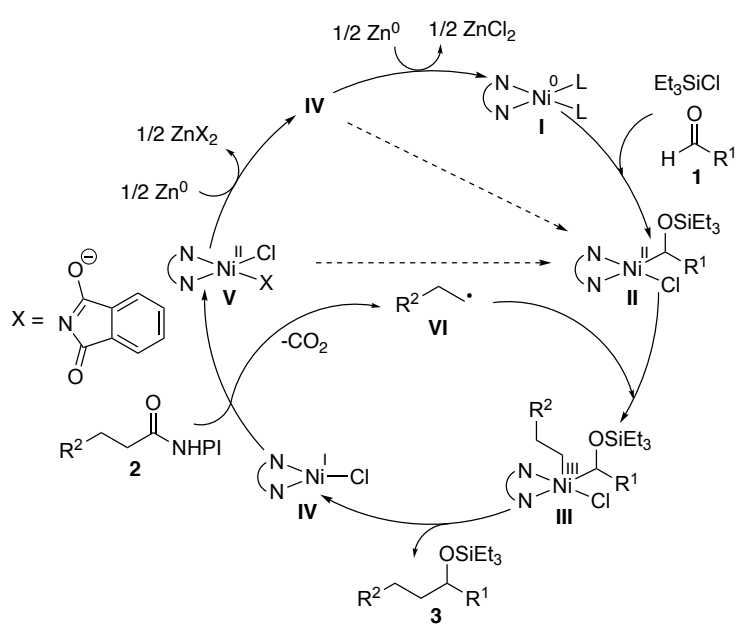

In conclusion, a highly effective decarboxylative alkylation of aliphatic aldehydes with redox- 
active esters has been developed. The procedure is broad in scope, tolerant of a wide array of functional groups, high-yielding, experimentally simply, and scalable. This process was extended to include the reductive cross-coupling of alkyl tosylates or epoxides with aliphatic aldehydes, thus providing a broad range of precursors derived from carboxylic acids, alcohols, or alkenes. Preliminary mechanistic experiments on this aldehyde - redox-active ester coupling are consistent with initial aldehyde activation to produce $\alpha$-silyloxyalkylnickel species as a key intermediate that is captured by free radicals generated from the redox-active ester. Future work will include efforts to further study the mechanism of these transformation and expand the scope in increasingly complex applications.

\section{ACKNOWLEDGEMENTS}

The authors thank the National Science Foundation (CHE-1954939) for support of this research. Dr. C. L. Cruz is thanked for many helpful discussions.

\section{REFERENCES}

1. Johansson Seechurn, C. C.; Kitching, M. O.; Colacot, T. J.; Snieckus, V., Palladium-Catalyzed Cross-Coupling: A Historical Contextual Perspective to the 2010 Nobel Prize. Angew. Chem. Int. Ed. 2012, 51, 5062-5085.

2. (a) Schneider, N.; Lowe, D. M.; Sayle, R. A.; Tarselli, M. A.; Landrum, G. A., Big Data from Pharmaceutical Patents: A Computational Analysis of Medicinal Chemists' Bread and Butter. J. Med. Chem. 2016, 59, 4385-4402; (b) Brown, D. G.; Bostrom, J., Analysis of Past and Present Synthetic Methodologies on Medicinal Chemistry: Where Have All the New Reactions Gone? J. Med. Chem. 2016, 59, 4443-4458.

3. (a) Tanaka, H.; Yamashita, S.; Hamatani, T.; Ikemoto, Y.; Torii, S., Lead-Promoted Allylation of Carbonyl Compounds with Allyl Bromide. Chem. Lett. 1986, 15, 1611-1614; (b) Luche, J. L.; Damiano, J. C., Ultrasounds in Organic Syntheses .1. Effect on the Formation of Lithium Organometallic Reagents. J. Am. Chem. Soc. 1980, 102, 7926-7927; (c) Boldrini, G. P.; Savoia, D.; Tagliavini, E.; Trombini, C.; Umani-Ronchi, A., Active Metals from Potassium-Graphite. Zinc-Graphite-Promoted Synthesis of /3Hydroxy Esters, Homoallylic Alcohols, and a-Methylene-Y-Butyrolactones. J. Org. Chem. 1983, 48, 4108-4111; (d) Imamoto, T.; Kusumoto, T.; Tawarayama, Y.; Sugiura, Y.; Mita, T.; Hatanaka, Y.; Yokoyama, M., Carbon-Carbon Bond-Forming Reactions Using Cerium Metal or Organocerium(lii) Reagents. J. Org. Chem. 1984, 49, 3904-3912; (e) Hiyama, T.; Obayashi, M.; Nakamura, A., GrignardType Carbonyl Addition of Allyl Unit with $\mathrm{MnCl}_{2}-\mathrm{LiAlH}_{4}$ Reagent. Organometallics 1982, 1, 1249-1251; (f) Nokaml, J.; Otera, J.; Sudo, T.; Okawara, R., Allylation of Aldehydes and Ketones in the Presence of Water by Allylic Bromides, Metallic Tin, and Aluminum. Organometallics 1983, 2, 191-193; (g) Blomberg, C.; Hartog, F. A., The Barbier Reaction - a One-Step Alternative for Syntheses Via Organomagnesium Compounds. Synthesis 1977, 18-30; (h) Petrier, C.; Einhorn, J.; Luche, J. L., Selective Tin and Zinc Mediafed Allylations of Carbonyl Compounds in Aqueous Media. Tetrahedron Lett. 1985, 26, 1449-1452.

4. (a) Avalos, M.; Babiano, R.; Cintas, P.; Jimenez, J. L.; Palacios, J. C., Synthetic Variations Based on Low-Valent Chromium: New Developments. Chem. Soc. Rev. 1999, 28, 169-177; (b) Furstner, A., Carbonminus Signcarbon Bond Formations Involving Organochromium(III) Reagents. Chem. Rev. 1999, 99, 991-1046; (c) Wessjohann, L. A.; Scheid, G., Recent Advances in Chromium(II)- and Chromium(III)Mediated Organic Synthesis. Synthesis 1999, 1-36; (d) Takac, K., Addition of Organochromium Reagents to Carbonyl Compounds. Org. React. 2004, 253-612; (e) Hargaden, G. C.; Guiry, P. J., The 
Development of the Asymmetric Nozaki-Hiyama-Kishi Reaction. Adv. Synth. Catal. 2007, 349, 24072424; (f) Lumbroso, A.; Cooke, M. L.; Breit, B., Catalytic Asymmetric Synthesis of Allylic Alcohols and Derivatives and Their Applications in Organic Synthesis. Angew. Chem. Int. Ed. 2013, 52, 1890-1932; (g) Zhang, G.; Tian, Q., Recent Advances in the Asymmetric Nozaki-Hiyama-Kishi Reaction. Synthesis 2016, 48, 4038-4049; (h) Gil, A.; Albericio, F.; Alvarez, M., Role of the Nozaki-Hiyama-Takai-Kishi Reaction in the Synthesis of Natural Products. Chem. Rev. 2017, 117, 8420-8446.

5. (a) Armstrong, R. W.; Beau, J. M.; Cheon, S. H.; Christ, W. J.; Fujioka, H.; Ham, W. H.; Hawkins, L. D.; Jin, H.; Kang, S. H.; Kishi, Y.; Martinelli, M. J.; Mcwhorter, W. W.; Mizuno, M.; Nakata, M.; Stutz, A. E.; Talamas, F. X.; Taniguchi, M.; Tino, J. A.; Ueda, K.; Uenishi, J.; White, J. B.; Yonaga, M., Total Synthesis of a Fully Protected Palytoxin Carboxylic-Acid. J. Am. Chem. Soc. 1989, 111, 7525-7530; (b) Armstrong, R. W.; Beau, J. M.; Cheon, S. H.; Christ, W. J.; Fujioka, H.; Ham, W. H.; Hawkins, L. D.; Jin, H.; Kang, S. H.; Kishi, Y.; Martinelli, M. J.; Mcwhorter, W. W.; Mizuno, M.; Nakata, M.; Stutz, A. E.; Talamas, F. X.; Taniguchi, M.; Tino, J. A.; Ueda, K.; Uenishi, J.; White, J. B.; Yonaga, M., Total Synthesis of Palytoxin Carboxylic-Acid and Palytoxin Amide. J. Am. Chem. Soc. 1989, 111, 7530-7533.

6. (a) Moragas, T.; Correa, A.; Martin, R., Metal-Catalyzed Reductive Coupling Reactions of Organic Halides with Carbonyl-Type Compounds. Chem. Eur. J. 2014, 20, 8242-8258; (b) Nimmagadda, S. K.; Korapati, S.; Dasgupta, D.; Malik, N. A.; Vinodini, A.; Gangu, A. S.; Kalidindi, S.; Maity, P.; Bondigela, S. S.; Venu, A.; Gallagher, W. P.; Aytar, S.; González-Bobes, F.; Vaidyanathan, R., Development and Execution of an $\mathrm{Ni}(\mathrm{li})$-Catalyzed Reductive Cross-Coupling of Substituted 2-Chloropyridine and Ethyl 3-Chloropropanoate. Org. Process Res. Dev. 2020, 24, 1141-1148; (c) Chen, R.; Couming, V.; Guzowski, J.; Irdam, E.; Kiesman, W. F.; Kwok, D.-I. A.; Liang, W.; Mack, T.; O’Brien, E. M.; Opalka, S. M.; Patience, D.; Sahli, S.; Walker, D. G.; Osei-Yeboah, F.; Gu, C.; Zhang, X.; Stöckli, M.; Stucki, T.; Matzinger, H.; Kuhn, R.; Thut, M.; Grohmann, M.; Haefner, B.; Lotz, J.; Nonnenmacher, M.; Cerea, P., Synthesis of Vixotrigine, a Voltage- and Use-Dependent Sodium Channel Blocker. Part 2: Development of a Late-Stage Process. Org. Process Res. Dev. 2020, 24, 2814-2829.

7. (a) Jin, H.; Uenishi, J.; Christ, W. J.; Kishi, Y., Catalytic Effect of Nickel(II) Chloride and Palladium(li) Acetate on Chromium(li)-Mediated Coupling Reaction of lodo Olefins with Aldehydes. J. Am. Chem. Soc. 1986, 108, 5644-5646; (b) Shi, A. F. a. N., Nozaki-Hiyama-Kishi Reactions Catalytic in Chromium. J. Am. Chem. Soc. 1996, 118, 12349-12357; (c) Namba, K.; Kishi, Y., New Catalytic Cycle for Couplings of Aldehydes with Organochromium Reagents. Org. Lett. 2004, 6, 5031-5033; (d) Namba, K.; Wang, J.; Cui, S.; Kishi, Y., Surprisingly Efficient Catalytic Cr-Mediated Coupling Reactions. Org. Lett. 2005, 7, 5421-5424; (e) Wessjohann, L. A.; Schrekker, H. S., Takai-Utimoto Reactions of Oxoalkylhalides Catalytic in Chromium and Cobalt. Tetrahedron Lett. 2007, 48, 4323-4325.

8. (a) Zhou, F.; Li, C. J., The Barbier-Grignard-Type Arylation of Aldehydes Using Unactivated Aryl lodides in Water. Nat. Commun. 2014, 5, 4254; (b) Swyka, R. A.; Zhang, W.; Richardson, J.; Ruble, J. C.; Krische, M. J., Rhodium-Catalyzed Aldehyde Arylation Via Formate-Mediated Transfer Hydrogenation: Beyond Metallic Reductants in Grignard/Nozaki-Hiyami-Kishi-Type Addition. J. Am. Chem. Soc. 2019, 141, 1828-1832.

9. Chang, H. T.; Jeganmohan, M.; Cheng, C. H., Highly Efficient Cyclization of O-lodobenzoates with Aldehydes Catalyzed by Cobalt Bidentate Phosphine Complexes: A Novel Entry to Chiral Phthalides. Chem. Eur. J. 2007, 13, 4356-4363.

10. (a) Majumdar, K. K.; Cheng, C. H., Ni(li)/Zn-Mediated Chemoselective Arylation of Aromatic Aldehydes: Facile Synthesis of Diaryl Carbinols. Org. Lett. 2000, 2, 2295-2298; (b) Choi, H. W.; Nakajima, K.; Demeke, D.; Kang, F. A.; Jun, H. S.; Wan, Z. K.; Kishi, Y., Asymmetric Ni(li)/Cr(li)- 
Mediated Coupling Reaction: Catalytic Process. Org. Lett. 2002, 4, 4435-4438; (c) Tan, Z.; Wan, X.; Zang, Z.; Qian, Q.; Deng, W.; Gong, H., Ni-Catalyzed Asymmetric Reductive Allylation of Aldehydes with Allylic Carbonates. Chem. Commun. 2014, 50, 3827-3830; (d) Garcia, K. J.; Gilbert, M. M.; Weix, D. J., Nickel-Catalyzed Addition of Aryl Bromides to Aldehydes to Form Hindered Secondary Alcohols. J. Am. Chem. Soc. 2019, 141, 1823-1827; (e) Zheng, Y. L.; Newman, S. G., Cross-Coupling Reactions with Esters, Aldehydes, and Alcohols. Chem. Commun. 2021, 57, 2591-2604; (f) Isbrandt, E. S.; Nasim, A.; Zhao, K.; Newman, S. G., Catalytic Aldehyde and Alcohol Arylation Reactions Facilitated by a 1,5Diaza-3,7-Diphosphacyclooctane Ligand. J. Am. Chem. Soc. 2021, 143, 14646-14656.

11. (a) Ni, S.; Padial, N. M.; Kingston, C.; Vantourout, J. C.; Schmitt, D. C.; Edwards, J. T.; Kruszyk, M. M.; Merchant, R. R.; Mykhailiuk, P. K.; Sanchez, B. B.; Yang, S.; Perry, M. A.; Gallego, G. M.; Mousseau, J. J.; Collins, M. R.; Cherney, R. J.; Lebed, P. S.; Chen, J. S.; Qin, T.; Baran, P. S., A Radical Approach to Anionic Chemistry: Synthesis of Ketones, Alcohols, and Amines. J. Am. Chem. Soc. 2019, 141, 67266739; (b) Gao, Y.; Hill, D. E.; Hao, W.; McNicholas, B. J.; Vantourout, J. C.; Hadt, R. G.; Reisman, S. E.; Blackmond, D. G.; Baran, P. S., Electrochemical Nozaki-Hiyama-Kishi Coupling: Scope, Applications, and Mechanism. J. Am. Chem. Soc. 2021, 143, 9478-9488.

12. (a) Frisch, A. C.; Beller, M., Catalysts for Cross-Coupling Reactions with Non-Activated Alkyl Halides. Angew. Chem. Int. Ed. 2005, 44, 674-688; (b) Everson, D. A.; Weix, D. J., Cross-Electrophile Coupling: Principles of Reactivity and Selectivity. J. Org. Chem. 2014, 79, 4793-4798; (c) Weix, D. J., Methods and Mechanisms for Cross-Electrophile Coupling of Csp² Halides with Alkyl Electrophiles. Acc. Chem. Res. 2015, 48, 1767-1775; (d) Kaga, A.; Chiba, S., Engaging Radicals in Transition MetalCatalyzed Cross-Coupling with Alkyl Electrophiles: Recent Advances. ACS. Catal. 2017, 7, 4697-4706. 13. (a) Goossen, L. J.; Rodriguez, N.; Goossen, K., Carboxylic Acids as Substrates in Homogeneous Catalysis. Angew. Chem. Int. Ed. 2008, 47, 3100-3120; (b) Noble, A.; McCarver, S. J.; MacMillan, D. W. C., Merging Photoredox and Nickel Catalysis: Decarboxylative Cross-Coupling of Carboxylic Acids with Vinyl Halides. J. Am. Chem. Soc. 2015, 137, 624-627.

14. (a) Cornella, J.; Edwards, J. T.; Qin, T.; Kawamura, S.; Wang, J.; Pan, C. M.; Gianatassio, R.; Schmidt, M.; Eastgate, M. D.; Baran, P. S., Practical Ni-Catalyzed Aryl-Alkyl Cross-Coupling of Secondary Redox-Active Esters. J. Am. Chem. Soc. 2016, 138, 2174-2177; (b) Huihui, K. M.; Caputo, J. A.; Melchor, Z.; Olivares, A. M.; Spiewak, A. M.; Johnson, K. A.; DiBenedetto, T. A.; Kim, S.; Ackerman, L. K.; Weix, D. J., Decarboxylative Cross-Electrophile Coupling of N-Hydroxyphthalimide Esters with Aryl lodides. J. Am. Chem. Soc. 2016, 138, 5016-5019; (c) Jamison, C. R.; Overman, L. E., Fragment Coupling with Tertiary Radicals Generated by Visible-Light Photocatalysis. Acc. Chem. Res. 2016, 49, 1578-1586; (d) Lu, X.; Xiao, B.; Liu, L.; Fu, Y., Formation of $\mathrm{C}\left(\mathrm{sp}^{3}\right)-\mathrm{C}\left(\mathrm{sp}^{3}\right)$ Bonds through NickelCatalyzed Decarboxylative Olefin Hydroalkylation Reactions. Chem. Eur. J. 2016, 22, 11161-11164; (e) Qin, T.; Cornella, J.; Li, C.; Malins, L. R.; Edwards, J. T.; Kawamura, S.; Maxwell, B. D.; Eastgate, M. D.; Baran, P. S., A General Alkyl-Alkyl Cross-Coupling Enabled by Redox-Active Esters and Alkylzinc Reagents. Science 2016, 352, 801-805; (f) Toriyama, F.; Cornella, J.; Wimmer, L.; Chen, T. G.; Dixon, D. D.; Creech, G.; Baran, P. S., Redox-Active Esters in Fe-Catalyzed C-C Coupling. J. Am. Chem. Soc. 2016, 138, 11132-11135; (g) Wang, J.; Qin, T.; Chen, T. G.; Wimmer, L.; Edwards, J. T.; Cornella, J.; Vokits, B.; Shaw, S. A.; Baran, P. S., Nickel-Catalyzed Cross-Coupling of Redox-Active Esters with Boronic Acids. Angew. Chem. Int. Ed. 2016, 55, 9676-9679; (h) Edwards, J. T.; Merchant, R. R.; McClymont, K. S.; Knouse, K. W.; Qin, T.; Malins, L. R.; Vokits, B.; Shaw, S. A.; Bao, D. H.; Wei, F. L.; Zhou, T.; Eastgate, M. D.; Baran, P. S., Decarboxylative Alkenylation. Nature 2017, 545, 213-218; (i) Huang, L.; Olivares, A. M.; Weix, D. J., Reductive Decarboxylative Alkynylation of N- 
Hydroxyphthalimide Esters with Bromoalkynes. Angew. Chem. Int. Ed. 2017, 56, 11901-11905; (j) Sandfort, F.; O'Neill, M. J.; Cornella, J.; Wimmer, L.; Baran, P. S., Alkyl-(Hetero)Aryl Bond Formation Via Decarboxylative Cross-Coupling: A Systematic Analysis. Angew. Chem. Int. Ed. 2017, 56, 33193323; (k) Smith, J. M.; Qin, T.; Merchant, R. R.; Edwards, J. T.; Malins, L. R.; Liu, Z.; Che, G.; Shen, Z.; Shaw, S. A.; Eastgate, M. D.; Baran, P. S., Decarboxylative Alkynylation. Angew. Chem. Int. Ed. 2017, 56, 11906-11910; (I) Suzuki, N.; Hofstra, J. L.; Poremba, K. E.; Reisman, S. E., Nickel-Catalyzed Enantioselective Cross-Coupling of N-Hydroxyphthalimide Esters with Vinyl Bromides. Org. Lett. 2017, 19, 2150-2153; (m) Bernhard, S. S. R.; Locke, G. M.; Plunkett, S.; Meindl, A.; Flanagan, K. J.; Senge, M. O., Cubane Cross-Coupling and Cubane-Porphyrin Arrays. Chem. Eur. J. 2018, 24, 1026-1030; (n) Chen, T. G.; Barton, L. M.; Lin, Y.; Tsien, J.; Kossler, D.; Bastida, I.; Asai, S.; Bi, C.; Chen, J. S.; Shan, M.; Fang, H.; Fang, F. G.; Choi, H. W.; Hawkins, L.; Qin, T.; Baran, P. S., Building C(Sp(3))-Rich Complexity by Combining Cycloaddition and C-C Cross-Coupling Reactions. Nature 2018, 560, 350354; (o) Liu, X. G.; Zhou, C. J.; Lin, E.; Han, X. L.; Zhang, S. S.; Li, Q.; Wang, H., Decarboxylative Negishi Coupling of Redox-Active Aliphatic Esters by Cobalt Catalysis. Angew. Chem. Int. Ed. 2018, 57, 13096-13100; (p) Ni, S.; Garrido-Castro, A. F.; Merchant, R. R.; de Gruyter, J. N.; Schmitt, D. C.; Mousseau, J. J.; Gallego, G. M.; Yang, S.; Collins, M. R.; Qiao, J. X.; Yeung, K. S.; Langley, D. R.; Poss, M. A.; Scola, P. M.; Qin, T.; Baran, P. S., A General Amino Acid Synthesis Enabled by Innate Radical Cross-Coupling. Angew. Chem. Int. Ed. 2018, 57, 14560-14565; (q) Proctor, R. S. J.; Davis, H. J.; Phipps, R. J., Catalytic Enantioselective Minisci-Type Addition to Heteroarenes. Science 2018, 360, 419-422; (r) Wang, J.; Lundberg, H.; Asai, S.; Martin-Acosta, P.; Chen, J. S.; Brown, S.; Farrell, W.; Dushin, R. G.; O'Donnell, C. J.; Ratnayake, A. S.; Richardson, P.; Liu, Z.; Qin, T.; Blackmond, D. G.; Baran, P. S., Kinetically Guided Radical-Based Synthesis of $\mathrm{C}\left(\mathrm{sp}^{3}\right)-\mathrm{C}\left(\mathrm{sp}^{3}\right)$ Linkages on DNA. Proc. Natl. Acad. Sci. U. S. A. 2018, 115, E6404-E6410; (s) Chen, T. G.; Zhang, H.; Mykhailiuk, P. K.; Merchant, R. R.; Smith, C. A.; Qin, T.; Baran, P. S., Quaternary Centers by Nickel-Catalyzed Cross-Coupling of Tertiary Carboxylic Acids and (Hetero)Aryl Zinc Reagents. Angew. Chem. Int. Ed. 2019, 58, 2454-2458; (t) Fu, M. C.; Shang, R.; Zhao, B.; Wang, B.; Fu, Y., Photocatalytic Decarboxylative Alkylations Mediated by Triphenylphosphine and Sodium lodide. Science 2019, 363, 1429-1434; (u) Lu, X.; Wang, X. X.; Gong, T. J.; Pi, J. J.; He, S. J.; Fu, Y., Nickel-Catalyzed Allylic Defluorinative Alkylation of Trifluoromethyl Alkenes with Reductive Decarboxylation of Redox-Active Esters. Chem. Sci. 2019, 10, 809-814; (v) Ni, S.; Padial, N. M.; Kingston, C.; Vantourout, J. C.; Schmitt, D. C.; Edwards, J. T.; Kruszyk, M. M.; Merchant, R. R.; Mykhailiuk, P. K.; Sanchez, B. B.; Yang, S.; Perry, M. A.; Gallego, G. M.; Mousseau, J. J.; Collins, M. R.; Cherney, R. J.; Lebed, P. S.; Chen, J. S.; Qin, T.; Baran, P. S., A Radical Approach to Anionic Chemistry: Synthesis of Ketones, Alcohols, and Amines. J. Am. Chem. Soc. 2019, 141, 67266739; (w) Wang, J.; Cary, B. P.; Beyer, P. D.; Gellman, S. H.; Weix, D. J., Ketones from Nickel-Catalyzed Decarboxylative, Non-Symmetric Cross-Electrophile Coupling of Carboxylic Acid Esters. Angew. Chem. Int. Ed. 2019, 58, 12081-12085.

15. (a) Cruz, C. L.; Montgomery, J., Nickel-Catalyzed Reductive Coupling of Unactivated Alkyl Bromides and Aliphatic Aldehydes. Chem. Sci. 2021, 12, 11995-12000; (b) Xiao, J.; Montgomery, J., Nickel-Catalyzed Defluorinative Coupling of Aliphatic Aldehydes with Trifluoromethyl Alkenes. ChemRxiv 2021, 10.33774/chemrxiv-32021-hsrb33772.

16. (a) Gaich, T.; Baran, P. S., Aiming for the Ideal Synthesis. J. Org. Chem. 2010, 75, 4657-4673; (b) Li, Z.; Sun, W.; Wang, X.; Li, L.; Zhang, Y.; Li, C., Electrochemically Enabled, Nickel-Catalyzed Dehydroxylative Cross-Coupling of Alcohols with Aryl Halides. J. Am. Chem. Soc. 2021, 143, 35363543. 
17. (a) Liu, J. H.; Yang, C. T.; Lu, X. Y.; Zhang, Z. Q.; Xu, L.; Cui, M.; Lu, X.; Xiao, B.; Fu, Y.; Liu, L., Copper-Catalyzed Reductive Cross-Coupling of Nonactivated Alkyl Tosylates and Mesylates with Alkyl and Aryl Bromides. Chem. Eur. J. 2014, 20, 15334-15338; (b) Molander, G. A.; Traister, K. M.; O'Neill, B. T., Engaging Nonaromatic, Heterocyclic Tosylates in Reductive Cross-Coupling with Aryl and Heteroaryl Bromides. J. Org. Chem. 2015, 80, 2907-2911; (c) Komeyama, K.; Ohata, R.; Kiguchi, S.; Osaka, I., Highly Nucleophilic Vitamin B12-Assisted Nickel-Catalysed Reductive Coupling of Aryl Halides and Non-Activated Alkyl Tosylates. Chem. Commun. 2017, 53, 6401-6404; (d) Wang, J.; Zhao, J.; Gong, H., Nickel-Catalyzed Methylation of Aryl Halides/Tosylates with Methyl Tosylate. Chem. Commun. 2017, 53, 10180-10183; (e) Komeyama, K.; Yamahata, Y.; Osaka, I., Nickel and Nucleophilic Cobalt-Catalyzed Trideuteriomethylation of Aryl Halides Using Trideuteriomethyl P-Toluenesulfonate. Org. Lett. 2018, 20, 4375-4378; (f) Duan, J.; Du, Y. F.; Pang, X.; Shu, X. Z., Ni-Catalyzed CrossElectrophile Coupling between Vinyl/Aryl and Alkyl Sulfonates: Synthesis of Cycloalkenes and Modification of Peptides. Chem. Sci. 2019, 10, 8706-8712.

18. (a) Cohen, T.; Jeong, I. H.; Mudryk, B.; Bhupathy, M.; Awad, M. M. A., Synthetically Useful Beta.Lithioalkoxides from Reductive Lithiation of Epoxides by Aromatic Radical Anions. J. Org. Chem. 1990, 55, 1528-1536; (b) Smith, J. G., Synthetically Useful Reactions of Epoxides. Synthesis-Stuttgart 1984, 629-656; (c) Molinaro, C.; Jamison, T. F., Catalytic Reductive Coupling of Epoxides and Aldehydes: Epoxide-Ring Opening Precedes Carbonyl Reduction. Angew. Chem. Int. Ed. 2004, 44, 129-132; (d) Nielsen, D. K.; Doyle, A. G., Nickel-Catalyzed Cross-Coupling of Styrenyl Epoxides with Boronic Acids. Angew. Chem. Int. Ed. 2011, 50, 6056-6059; (e) Zhao, Y.; Weix, D. J., Nickel-Catalyzed Regiodivergent Opening of Epoxides with Aryl Halides: Co-Catalysis Controls Regioselectivity. J. Am. Chem. Soc. 2014, 136, 48-51; (f) Zhao, Y.; Weix, D. J., Enantioselective Cross-Coupling of Meso-Epoxides with Aryl Halides. J. Am. Chem. Soc. 2015, 137, 3237-3240; (g) Lau, S. H.; Borden, M. A.; Steiman, T. J.; Wang, L. S.; Parasram, M.; Doyle, A. G., Ni/Photoredox-Catalyzed Enantioselective Cross-Electrophile Coupling of Styrene Oxides with Aryl lodides. J. Am. Chem. Soc. 2021, 143, 15873-15881.

19. (a) Hoveyda, A. H.; Evans, D. A.; Fu, G. C., Substrate-Directable Chemical-Reactions. Chem. Rev. 1993, 93, 1307-1370; (b) Müller, M.; Bode, S. E.; Wolberg, M., Stereoselective Synthesis of 1,3-Diols. Synthesis 2006, 2006, 557-588; (c) Chen, Y.; Chen, C.; Wu, X., Dicarbonyl Reduction by Single Enzyme for the Preparation of Chiral Diols. Chem. Soc. Rev. 2012, 41, 1742-1753; (d) Gupta, P.; Mahajan, N.; Taneja, S. C., Recent Advances in the Stereoselective Synthesis of 1,3-Diols Using Biocatalysts. Catal. Sci. Technol. 2013, 3, 2462-2480.

20. (a) Biswas, S.; Weix, D. J., Mechanism and Selectivity in Nickel-Catalyzed Cross-Electrophile Coupling of Aryl Halides with Alkyl Halides. J. Am. Chem. Soc. 2013, 135, 16192-16197; (b) Breitenfeld, J.; Ruiz, J.; Wodrich, M. D.; Hu, X., Bimetallic Oxidative Addition Involving Radical Intermediates in Nickel-Catalyzed Alkyl-Alkyl Kumada Coupling Reactions. J. Am. Chem. Soc. 2013, 135, 12004-12012; (c) Zhao, C.; Jia, X.; Wang, X.; Gong, H., Ni-Catalyzed Reductive Coupling of Alkyl Acids with Unactivated Tertiary Alkyl and Glycosyl Halides. J. Am. Chem. Soc. 2014, 136, 17645-17651.

21. Gilbert, M. M.; Trenerry, M. J.; Longley, V. R.; Berry, J. F.; Weix, D. J., Ligand-Metal Cooperation Enables C-C Activation Cross-Coupling Reactivity of Cyclopropyl Ketones. ChemRxiv 2021, 10.33774/chemrxiv-32021-hjdbr.

22. Ogoshi, S.; Kamada, H.; Kurosawa, H., Reaction of (Eta(2)-Arylaldehyde)Nickel(0) Complexes with Me3six $(\mathrm{X}=\mathrm{Otf}, \mathrm{Cl})$. Application to Catalytic Reductive Homocoupling Reaction of Arylaldehyde. Tetrahedron 2006, 62, 7583-7588.

23. Ju, L.; Lin, Q.; LiBretto, N. J.; Wagner, C. L.; Hu, C. T.; Miller, J. T.; Diao, T., Reactivity of (Bi- 
Oxazoline)Organonickel Complexes and Revision of a Catalytic Mechanism. J. Am. Chem. Soc. 2021, 143, 14458-14463.

24. Michel, N. W. M.; Edjoc, R. K.; Fagbola, E.; Hughes, J. M. E.; Campeau, L.-C.; Rousseaux, S. A. L., Nickel-Catalyzed Reductive Arylation of Redox Active Esters for the Synthesis of Alpha-Aryl Nitriles - Role of a Chlorosilane Additive. ChemRxiv 2021, 10.26434/chemrxiv.14450007.v14450002. 